\title{
Aurora B expression modulates paclitaxel response in non-small cell lung cancer
}

\author{
Ahmed SK Al-Khafaji ${ }^{1,2}$, Michael PA Davies ${ }^{1}$, Janet M Risk ${ }^{3}$, Michael W Marcus ${ }^{1}$, Maria Koffa ${ }^{4}$, John R Gosney ${ }^{1}$, \\ Richard J Shaw ${ }^{3}$, John K Field ${ }^{1}$ and Triantafillos Liloglou*,1 \\ ${ }^{1}$ Roy Castle Lung Cancer Research Programme, Department of Molecular and Clinical Cancer Medicine, Institute of Translational \\ Medicine, University of Liverpool, Liverpool, UK; ${ }^{2}$ Department of Biology, Collage of Science, University of Baghdad, Baghdad, \\ Iraq; ${ }^{3}$ Mersey Head and Neck Oncology Research Group, Department of Molecular and Clinical Cancer Medicine, Institute of \\ Translational Medicine, University of Liverpool, Liverpool, UK and ${ }^{4}$ Department of Molecular Biology and Genetics, Democritus \\ University of Thrace, Alexandroupolis, Greece
}

Background: Taxanes are mitotic poisons widely used in the treatment of non-small cell lung cancer (NSCLC), however, little is known about potential molecular modulators of response to these compounds. Aurora B (AURKB) is a critical regulator of the mitotic spindle assembly, previously shown overexpressed in NSCLC. Here we investigated the hypothesis that AURKB expression modulates the efficacy of taxanes in NSCLC cells.

Methods: AURKB mRNA expression was determined by qPCR in 132 frozen NSCLC tissues and nine NSCLC cell lines. Aurora B expression was knocked down in cell lines using multiple shRNA constructs. Barasertib was used to specifically inhibit AURKB activity, determined by the level of H3S10 phosphorylation.

Results: Frequent AURKB mRNA upregulation was observed in NSCLC tissues $(P<0.0001)$, being more prominent in squamous carcinomas $(P<0.0001)$. Aurora $B$ expression in cell lines strongly correlated with sensitivity to both docetaxel $(P=0.004)$ and paclitaxel $(P=0.007)$. Aurora B knockdown derivatives consistently showed a dose-dependent association between low-AURKB expression and resistance to paclitaxel. Specific chemical inhibition of Aurora B activity also demonstrated a strong dosedependent efficiency in triggering paclitaxel resistance.

Conclusions: Aurora B activity is an important modulator of taxane response in NSCLC cells. This may lead to further insights into taxane sensitivity of NSCLC tumours.

Lung cancer is currently responsible for almost a quarter of cancer-related deaths in the developed countries. Non-small cell lung carcinoma (NSCLC) is the most frequent type with adenocarcinoma (AdC) and squamous cell carcinoma (SqCC) being the most common sybtypes (Travis et al, 2013). Despite the recent advances in targeted therapies for lung cancer, including agents targeting EGFR, VEGF and ALK, the therapeutic regimes currently used for NSCLC treatment are largely still based on the use of organometallics and anti-mitotics (Camidge et al, 2014).
Taxanes are microtubule targeting agents (MTAs), which are used to treat a variety of human cancers (Del Mastro et al, 2013; Isonishi et al, 2013; Van Veldhuizen et al, 2003) including lung carcinomas (Maemondo et al, 2014). Paclitaxel and Docetaxel represent the most prominent members of the taxane family and have manifested significant activity, mainly used as part of complex chemotherapeutic regimens (Tsao et al, 2011; Oh et al, 2013) or less frequently as monotherapy (Chu et al, 2005; Herbst et al, 2010). The cytotoxic action of these compounds is mediated primarily through their binding

*Correspondence: Dr T Liloglou; E-mail: tliloglo@liverpool.ac.uk

Revised 8 December 2016; accepted 15 December 2016; published online 17 January 2017

(c) 2017 Cancer Research UK. All rights reserved 0007-0920/17 
of $\beta$ tubulin monomers, leading to microtubule stabilisation, thus blocking their depolymerisation and subsequently triggering cell cycle arrest at the G2/M phase (Monzo et al, 1999). However, many other pathways may also be involved in modulating their therapeutic effect. Thus far, the range of relevant interactions is not clear and the mechanisms related to taxane resistance acquisition are largely unexplored, in spite of their long clinical use in cancer therapeutics (Murray et al, 2012; Che et al, 2013). Although an increasing number of targeted therapeutic agents have come into clinical use (Kris et al, 2014), it is estimated that taxanes will still be used in chemotherapy regimens for lung cancer treatment for the foreseeable future (Cagle and Chirieac, 2012). Therefore, the identification of relevant response predictors will highly benefit clinical practice by stratifying patients into suitable currently available schemes (Cottini and Lautenschlaeger, 2013).

A number of genes have been previously implicated in taxane resistance in NSCLC. Functional p53 was shown to induce sensitivity to docetaxel (Jinturkar et al, 2012) and paclitaxel (Guntur et al, 2010) in NSCLC cell lines. A phase-III randomised trial showed that KRAS mutations decrease response of NSCLC to therapy involving paclitaxel, carboplatin and erlotinib (Eberhard et al, 2005). It is reasonable to hypothesise that the expression of genes involved in mitotic spindle formation may be predictors of sensitivity to taxanes. Tubulin $\beta$ III mutations have been associated with resistance to taxanes in NSCLC patients (Kaira et al, 2013) as well as cultured lung cancer cells (Kavallaris et al, 1999). However, the inclusion of TUBB3 expression levels in the prediction model for docetaxel sensitivity shows no improvement while certain drug pump genes (MRP5 and MVP) and detoxification genes appear as better predictors (Glaysher et al, 2009). The CHFR gene has also been suggested as a potential predictor of response of NSCLC patients to first-line therapy with carboplatin and paclitaxel (Pillai et al, 2013). Nevertheless, the available information on taxane efficacy predictors does not provide conclusive evidence. Considering the role of Aurora kinases in spindle formation and the reported extent of their deregulation in cancer, one may hypothesise that Aurora-dependent modulation of taxane efficiency is probable.

Aurora kinase $B(A U R K B)$ is a member of the Aurora kinase subfamily of conserved Serine/Threonine kinases, which also includes Aurora A and Aurora C. Deregulation of Aurora kinases leads to impairment of mitotic spindle checkpoints causing abnormal spindle assembly (Fu et al, 2007). Aurora B is encoded by the $A U R K B$ gene $(17 \mathrm{p} 13.1)$ and plays a key role during mitosis by regulating chromosomal alignment, segregation and cytokinesis, as the catalytic protein of the chromosomal passenger complex. Activation of Aurora B by INCENP is required for promoting transfer of the chromosomal passenger complex (INCENP-Survivin-Borealin) to the spindle midzone during mitotic exit (Xu et al, 2009). It is localised to the centromere and is required for kinetochore localisation and chromosome attachment to the mitotic spindle (Hauf et al, 2003), as well as establishing the spindle assembly checkpoint to correct anomalous chromosome-kinetochore microtubule attachment before the cell enters anaphase (Carmena et al, 2012).

$A U R K B$ is frequently overexpressed in NSCLC (Vischioni et al, 2006) and is associated with genetic instability (Smith et al, 2005), aneuploidy and poor patient prognosis (Takeshita et al, 2013). However, high Aurora B kinase expression has been associated with improved relapse-free survival in ovarian cancer patients on taxane-based therapy (Beussel et al, 2012). Currently, there is very limited information on the potential impact of Aurora B on taxane response in cancer cells. In this study, we confirmed the extent of AURKB deregulation in NSCLC and utilised in vitro approaches to investigate the hypothesis that
AURKB activity may modulate and thus be predictive of the sensitivity to taxanes in NSCLC.

\section{METHODS}

Primary NSCLC tumour samples. This study was undertaken in association with the Liverpool Lung Project. Appropriate Ethical approval has been acquired and all patients have provided written informed consent. 132 snap-frozen tumour samples were obtained at surgery and included in the study; 56 from AdC and 76 from SqCC. Pathological review of the sections used in this study confirmed inclusion of only specimens with $>70 \%$ tumour cell content. In addition, 44 non-tumour paired surgical tissues (20 from AdC and 24 from SqCC patients) were available for analysis, taken from the distant edge of the lung resection. The clinicopathological characteristics of this cohort are provided in Supplementary Table 1 . The median age of those patients was 67 (45-82); 56 of the patients were females and 77 were males.

Cell lines and growth conditions. All cell lines in this study were authenticated using the GenePrint 10 System (Promega, Southampton, UK) and analysis on a 3130 Genetic Analyzer (Life Technologies, Paisley, UK) and mycoplasma tested utilising the e-MycoTM plus Mycoplasma PCR Detection Kit (Intron Biotechnology, Gyeonggi-do, Korea). Nine NSCLC cell lines (A549, Calu3, CALU6, CRL5802, CORL23, H358, LUDLU1, SKLU1 and SKMES1) were cultured in Dulbecco's Modified Eagle's Medium (DMEM)/Ham's Nutrient Mixture F-12 (1:1) containing 5\% foetal bovine serum (Sigma-Aldrich, Gillingham, UK). Non-tumourigenic immortalised human bronchial epithelial cells (HBEC3KT) along with their isogenic derivatives; p53 knockouts (HBEC3KT53), KRAS mutants (HBEC3KTR) and cells with both aberrations (HBEC3KTR53) were also employed in this study. Human bronchial epithelial cells were cultured in Keratinocyte-SFM medium supplemented with $50 \mu \mathrm{g} \mathrm{ml}^{-1}$ bovine pituitary extract (BPE) and $5 \mathrm{ng} \mathrm{ml}^{-1}$ human recombinant epidermal growth factor (rEGF; Life Technologies). All cell lines were maintained at $37^{\circ} \mathrm{C}, 5 \% \mathrm{CO}_{2}$.

Knockdown of AURKB by short hairpin RNA (shRNA). A549 and SK-MES1 cell lines were transfected with five different AURKB-targeting MISSION shRNA constructs (Sigma-Aldrich, clone numbers: TRCN0000000777, TRCN0000000776, TRCN000 0000778, TRCN0000000779 and TRCN0000010547) along with a scrambled control construct, using Attractene Transfection Reagent (Qiagen, Manchester, UK). Stable clones were selected by exposure to Puromycin (4 nM) and knockdown efficiency was confirmed by qPCR and western blotting.

AURKB overexpression. The AURKB-PCMV6-XL4 construct (Cat no. PCMV6XL4, SC117526 NM_004217 AURKB-OriGene, Rockville, MD, USA) was digested with PsiI (New England Biolabs, Herts, UK) and ligated with a Blasticidin cassette-containing fragment, which was derived by SmaI digestion of the pCMV/Bsd plasmid (Catalogue no. V510-20-Life Technologies). Standard blunt end ligation was performed using T4 DNA ligase (New England Biolabs). One Shot TOP10 Chemically Competent E. coli cells (Invitrogen, Paisley, UK) were transformed and clones were selected for validation. The derived constructs were confirmed by dideoxyterminator sequencing (Life Technologies).

CALU3 cell line was transfected with pCMV6-XL4-AURKB/Bsd recombinant plasmid using Attractene Transfection Reagent (Qiagen). Stable transfectant clones were selected in the presence of $5 \mu \mathrm{g} \mathrm{ml}{ }^{-1}$ Blasticidin (Sigma-Aldrich). mRNA overexpression of AURKB was confirmed by qPCR.

Taxane and AZD1152 (Barasertib) exposure experiments. Depending on the growth rate of each cell line, $5 \times 10^{4}$ to $8 \times 10^{4}$ cells were seeded in each well of flat-bottomed 48 -well plates in six 
replicates and cultured in $500 \mu \mathrm{l}$ of medium. After overnight incubation, the medium was replaced with media containing a range of Paclitaxel (Sigma-Aldrich) or Docetaxel (FLUKA) concentrations (0-35 nм) and/or Barasertib (Selleck Chemicals, Munich, Germany) (0-3.2 nM). Cells were incubated for $72 \mathrm{~h}$ with replenishment of medium with drug at $36 \mathrm{~h}$. Toxicity was measured by MTT assay. Briefly, $200 \mu \mathrm{l}$ of fresh medium containing $0.75 \mathrm{mg} \mathrm{ml}^{-1} 3-(4,5-$ dimethylthiazol-2-yl)-2,5-diphenyltetrazolium bromide (SigmaAldrich) was added and incubated at $37^{\circ} \mathrm{C}$ for $3 \mathrm{~h}$. Cells were lysed using $0.04 \mathrm{M} \mathrm{HCl}$ in isopropanol and the optical density (OD) was measured at $590 \mathrm{~nm}$ with $630 \mathrm{~nm}$ as reference in a GENios plate reader (Tecan, Männedorf, Switzerland).

DNA and RNA extraction, reverse transcription and qPCR. Deoxyribonucleic acid was extracted from cell lines and primary lung tumours using the DNeasy Blood and Tissue Kit (Qiagen). Total RNA was extracted using Direct-zol RNA MiniPrep Kit (Zymo Research, Irvine, CA, USA). Quality and quantity of DNA and RNA were determined using a NanoDrop 2000 Spectrophotometer (Thermo Scientific). In total, $200 \mathrm{ng}$ RNA was reverse transcribed using the high capacity cDNA Reverse Transcription Kit (Life Technologies). A predesigned FAM-labelled Taqman expression assay (Hs00945858_g1-Life Technologies) was employed to analyse $A U R K B$ mRNA expression, with a VIC-labelled ACTB Taqman assay (4326315E-Life Technologies) serving as endogenous control. Real-time PCR assays were performed in triplicate using a StepOnePlus Real-Time PCR System (Life Technologies). HBEC3KT RNA was used as calibrator for calculating delta-delta cycle thresholds $(\Delta \Delta \mathrm{Ct})$ and relative quantification values.

Western blotting. Cultured cells were lysed in SDS-based cell lysis buffer containing protease/phosphatase inhibitors and whole cell lysates were sonicated 10 times for $5-15 \mathrm{~s}$ with $10 \mathrm{~s}$ intervening

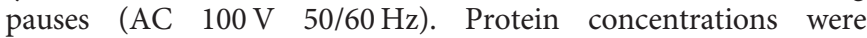
determined using the BCA assay (Thermo Scientific) on a NanoDrop 2000 Spectrophotometer (Thermo Scientific). Ten to fifty microgram of total protein was reduced by NuPAGE Reducing Agent (Life Technologies) and incubated at $70{ }^{\circ} \mathrm{C}$ for $10 \mathrm{~min}$.
Samples were run in NuPAGE Novex Bis-Tris Gels utilising NuPAGE Antioxidant containing NuPAGE MES Running Buffer (Life Technologies). Electroblotting on PVDF membranes was undertaken by iBlot Dry Blotting System (Life Technologies). The iBind Western System (Life Technologies) was employed for application of blocking, primary and secondary antibodies (at dilution $1: 1000$ ) and washing steps. Mouse monoclonal primary antibodies to total Histone H3 (phospho S10; ab14955) and $\beta$-actin (ab8226; Abcam) were used, while IRDye 800CW Goat Anti-Mouse (LI 925-32210) antibody (Odyssey - LI-COR Biosciences) served as secondary. The immune complexes were detected using Odyssey CLx Infrared Imaging System (Odyssey LI-COR Biosciences).

Statistical analysis. All statistical analyses were performed using IBM SPSS statistical software version 22.0 (Armonk, NY: IBM Corp) unless otherwise stated. Covariates were assessed for compliance to normal distribution graphically using histograms and by analytical methods using Kolmogorov-Smirnov/ShapiroWilk tests. In the absence of normality, Mann-Whitney, Wilcoxon rank or Kruskal-Wallis was employed to assess the difference in $A U R K B$ mRNA expression and response to taxanes. Kaplan-Meier method was employed for survival analysis and statistical differences between groups were examined with Log-rank test. The IC50 values were calculated using Prism 5 (GraphPad) in comparison to untreated cells at time 0 .

\section{RESULTS}

AURKB mRNA is overexpressed in NSCLC tissues and cell lines. mRNA expression profiling of $A U R K B$ in snap-frozen tissues demonstrated significant overexpression of the gene transcript in tumour tissue compared to the adjacent normal tissues (Mann-Whitney test, $P<0.0001$, Figure 1a). This overexpression was more profound in SqCC than AdCs (MannWhitney test, $P<0.0001$, Figure $1 \mathrm{~b})$. In addition, $A U R K B$

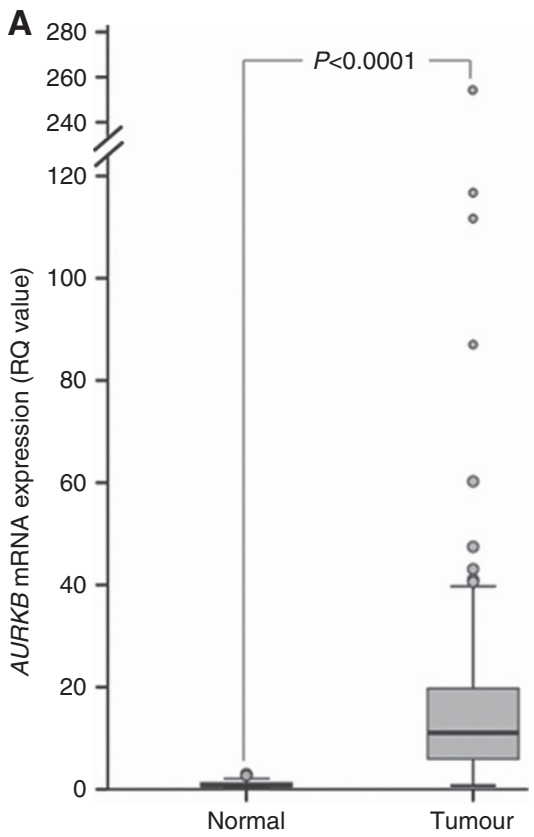

B

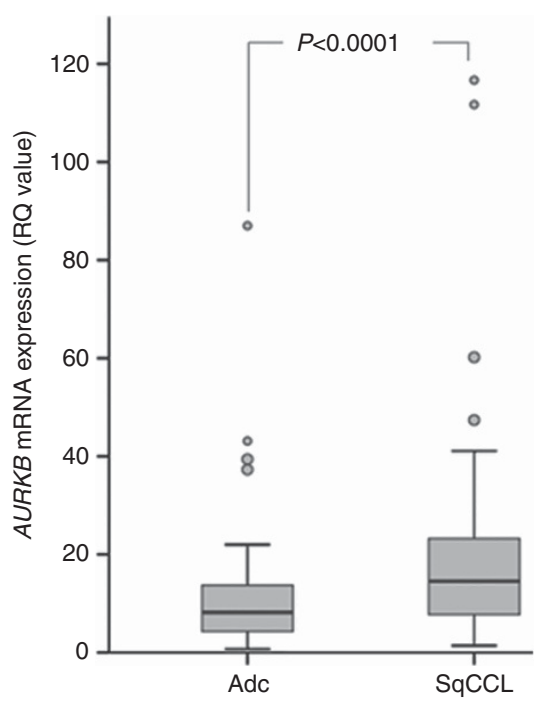

Figure 1. AURKB mRNA expression in primary NSCLC. Boxplots demonstrating AURKB mRNA expression in primary lung tumours compared to adjacent normal lung tissues $(\mathbf{A})$ and in squamous cell carcinomas $(\mathrm{SqCC}$ ) compared to adenocarcinomas (AdC) (B). $P$ values are derived from Mann-Whitney tests. Relative quantification was calculated using RNA from the non-tumourigenic cell line HBEC3KT as a calibrator. Larger circles represent outlier values ( $>1.5 \times$ interquartile range); smaller circles represent extreme values $(>3 \times$ interquartile range). 
expression was more elevated in higher pathological T stages (T1 vs T2, $P=0.012$, Supplementary Figure 1 ), however, this finding has to be treated with caution as the great majority of tumours in this sample set fall into the pT2 stage group $(n=101)$ while pT1 and pT3/4 group comprised 19 and 12 patients, respectively. This bias reflects the stage distribution among the operable NSCLC cases in the UK and therefore our access to the relevant tissue. $A U R K B$ upregulation did not demonstrate a significant impact on overall survival (OS) in this set, although a non-significant trend was demonstrated in adenocarcinoma patients $(P=0.079$, Supplementary Figure 2). Survival analysis using the top and bottom terciles instead of the median did not result in a significant relationship, most probably due to the significant reduction of numbers of patients in these groups. This weak correlation prompted us to check the available data in the public domain. In there (http://kmplot.com/analysis/index.php?p=service\&cancer=lung) when selecting all NSCLC, AURKB expression significantly reduces survival $\left(P<10^{-16}\right)$. However when selecting only the NSCLC group subjected to chemotherapy this correlation is not true $(P=0.3)$. No further associations were found between $A U R K B$ mRNA expression and age, gender, clinical stage or nodal status in our patient set.

$A U R K B$ mRNA expression profiling was also undertaken in a panel of lung cancer cell lines, along with immortalised normal human bronchial epithelial cells (HBEC3KT and its isogenic p53 knockout and KRAS mutant derivatives). AURKB expression was variable among the lung cancer cell lines, however, it was markedly higher in comparison to that of non-tumourigenic HBECs (Figure 2). It is of note that among HBECs AURKB mRNA expression was higher in the p53 knockout derivatives (HBEC3KTp53 and HBEC3KTRp53) while a borderline reduction was seen in KRAS mutants (HBEC3KTR).

Modulation of NSCLC cells resistance to taxanes by AURKB expression. The IC50 values for paclitaxel and docetaxel toxicity among the available lung cell lines were determined following treatment with a range of concentrations (1-35 nM) of the two drugs (Supplementary Table 2). IC50s for docetaxel were consistently lower than those of paclitaxel with one exception (SKLU1 cells). Interestingly, mRNA expression of AURKB in NSCLC cell lines inversely correlated with resistance to both docetaxel (Spearman's test, rho $=-0.850, P=0.004$ ) and paclitaxel (rho $=-0.817, P=0.007$, Supplementary Table 2). We explored the hypothesis this effect simply being a correlation between taxane resistance and doubling time (Supplementary Table 3). However, our results did not demonstrate any correlation between doubling time with either AURKB expression (Spearman's test, rho $=-533, P=0.139$ ) or resistance to paclitaxel $(\mathrm{rho}=0.333, P=0.381)$ or docetaxel $\quad(\mathrm{rho}=0.500$, $P=0.170$, Supplementary Table 2).

In order to further explore the possible modulation of taxane response by $A U R K B$, we investigated the resistance of lung cancer cell lines to paclitaxel by (a) knocking down $A U R K B$ expression and (b) chemically inhibiting its activity. Successful $A U R K B$ knock down clones were derived from A549 and SK-MES1 cells using different shRNA constructs. Knockdown efficiency was assessed by qPCR and western blot (Figure 3). The clones, as expected, demonstrated variable knock down efficiency. When exposing these clones to paclitaxel it was apparent that response to the drug inversely correlated to the level of $A U R K B$ mRNA expression in a dose-dependent manner. This was true for both clones derived from A549 and four clones derived from SK-MES1, while scrambled shRNA clones did not demonstrate altered response to paclitaxel when compared to the paternal cells (Figure 3).

Additional support to the knock down experiments came from overexpressing AURKB in Calu3 cell line. A stable overexpressing clone derived from these cells demonstrated higher sensitivity to paclitaxel (Supplementary Figure 6).

Selective inhibition of AURKB desensitises NSCLC cells to paclitaxel. In order to gain additional supporting evidence, we undertook selective inhibition of Aurora B using a highly specific Aurora B inhibitor (Barasertib). After experimentally determining the IC50s of Barasertib in A549, SK-MES1 and SKLU1 as 0.91 .2 and $2.3 \mathrm{nM}$, respectively, we simultaneously exposed cells to paclitaxel and a range of Barasertib concentrations. AURKB

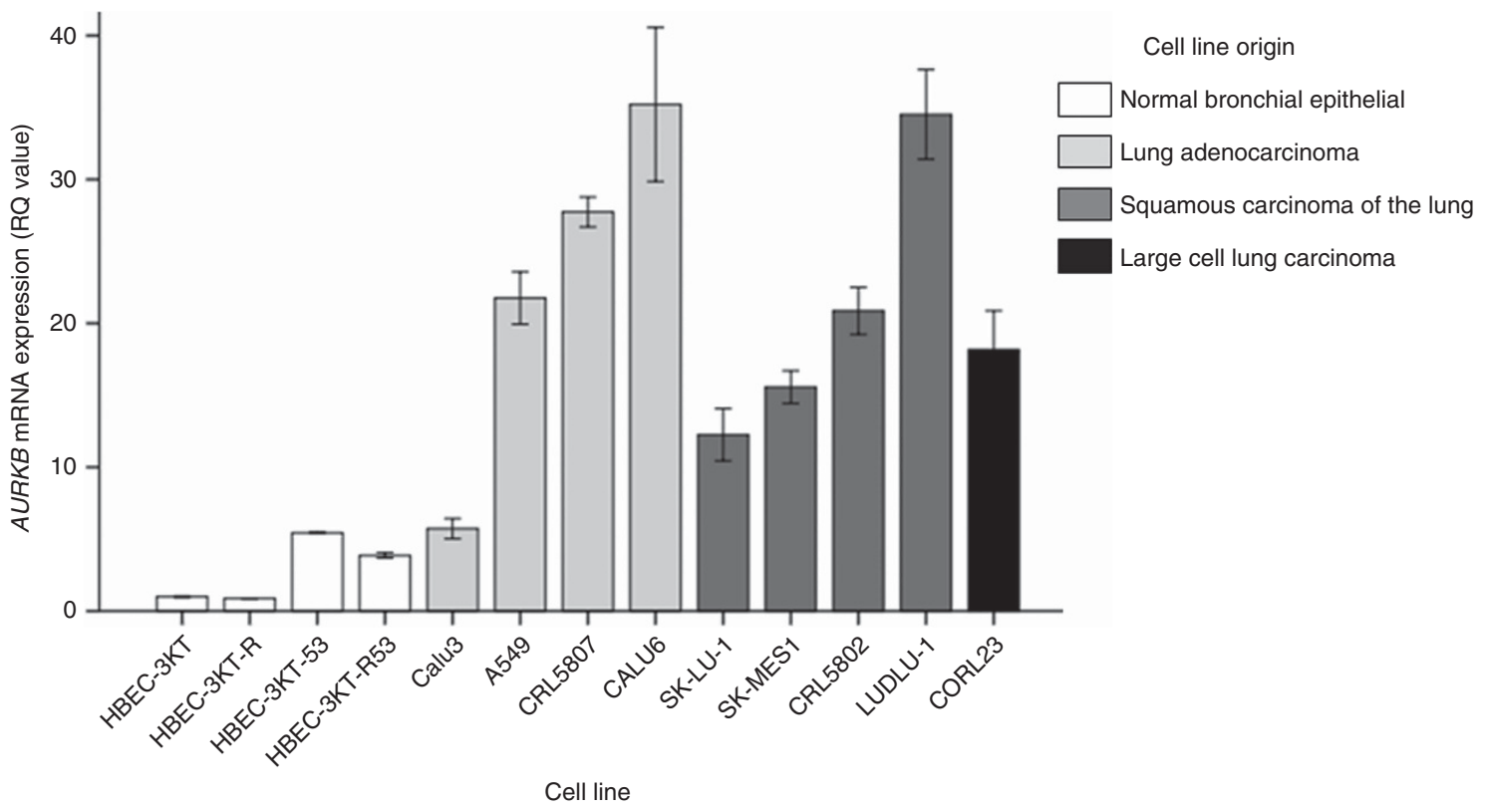

Figure 2. AURKB mRNA expression in human bronchial epithelial cells (HBEC) and lung cancer cell lines. Bars represent mean values from six biological repeats and error bars represent standard error of the mean. All NSCLC cell lines show a higher expression than the non-tumourigenic immortalised bronchial cells (HBEC3KT). Also, an increased AURKB expression is shown in the isogenic p53 derivatives (3KT-53 and 3KT-R53) of the latter. 
inhibition was confirmed by measuring phosphorylation of histone 3 serine 10 ( $\mathrm{H} 3 \mathrm{~S} 10)$, which is on one of its prime substrates (Supplementary Figure 3). In addition, we confirmed that Barasertib exposure does not alter the mRNA expression of AURKB (Supplementary Figure 3). Barasertib-mediated AURKB inhibition clearly demonstrated a dose-dependent effect on paclitaxel efficiency; increased Barasertib concentrations resulted in increased resistance to paclitaxel in all three cell lines (Figure 4). We subsequently confirmed the Barasertib-mediated resistance to paclitaxel in the remaining NSCLC cell lines included in this study (LUDLU1, CRL5807, CRL5802, CORL23, CALU6 and CALU3) as well as all the AURKB knockdown derivatives from SKMES and A549 (Supplementary Figure 4 and 5). It is of note that in the AURKB knockdown clones the Barasertib effect, while still visible, is reduced in comparison to the non-AURKB engineered NSCLC cell lines, as expected.

\section{DISCUSSION}

Aurora B kinase is an important contributor to the mitotic spindle assembly and its overexpression in human cancer has been frequently reported (Sorrentino et al, 2005; Lin et al, 2010; Pohl et al, 2011), therefore attracting significant interest in both cancer biology and therapeutics. In this study, we hypothesised that Aurora B activity may be implicated in modulating cellular response to taxanes, due to its role in mitotic spindle function, which is the target of these compounds. mRNA profiling of our
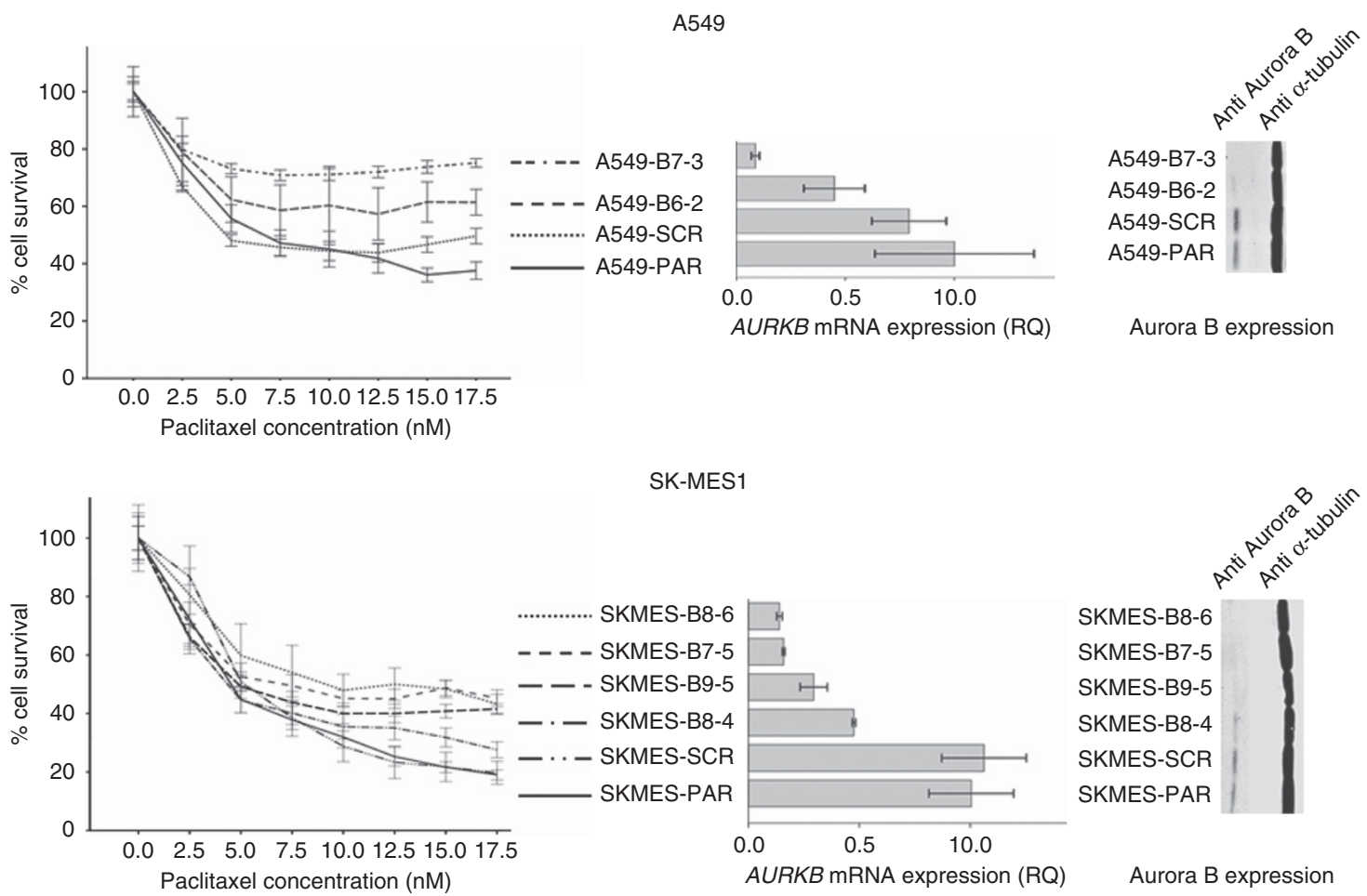

Figure 3. Paclitaxel response of lung cancer cell lines A549 and SK-MES1 and their AURKB knock down derivative clones in relation to AURKB mRNA and protein expression. Error bars in both the line graphs and the expression bar charts represent $95 \% \mathrm{Cl}$. PAR, parental; SCR, scrambled; $-B x-y$, knockdown clones where $\mathrm{x}$ is the shRNA construct and $\mathrm{y}$ is the clone number from this transfection. It is of note that the different knockdown efficiencies in the clones are associated with inverse impact on paclitaxel sensitivity.
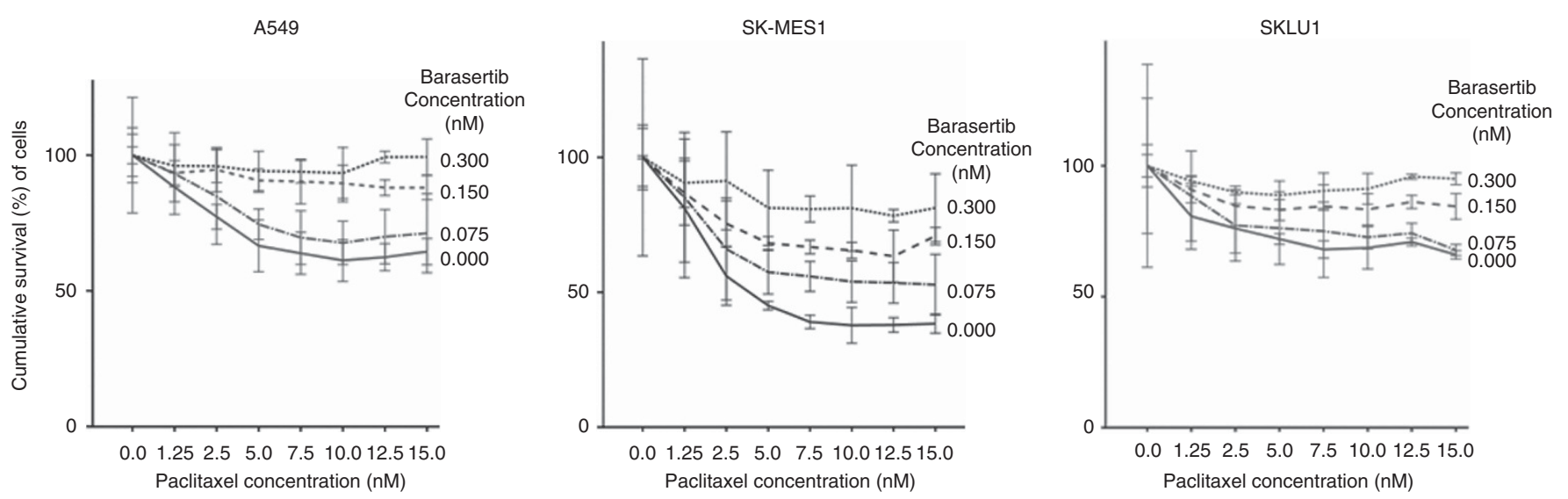

Figure 4. Sensitivity of lung cancer cell lines to paclitaxel in the presence of the highly selective Aurora B inhibitor (Barasertib). Error bars represent $95 \% \mathrm{Cl}$. A clear quantitative effect is demonstrated where increasing concentrations of Barasertib, and therefore, inhibition of AURKB activity, is associated with increased resistance to paclitaxel. 
NSCLC patient cohort confirmed the extensive overexpression of this gene, as previously reported (Takeshita et al, 2013; Vischioni et al, 2006; Smith et al, 2005). AURKB overexpression seems to be the main abnormality related with this gene in NSCLC. The relevant entries in COSMIC database (http://cancer.sanger.ac.uk/ cosmic) report low number of point mutations (5 out of 1985 , $0.2 \%)$, copy number variations (4 out of $843,0.4 \%$ ) and frequent overexpression (139 out of 1008, 13.8\%). In addition to the frequency difference in histological NSCLC types, AURKB overexpression appeared to be weakly associated with higher pathological stages. This observation may indicate that $A U R K B$ expression deregulation is a progressive phenomenon; however, one has to replicate this finding in additional cohorts. Nevertheless, investigation of the data available in TCGA study (http:// www.cbioportal.org/index.do) do not show any $\mathrm{pT}$ stage related differences in lung adenocarcinoma or tumour dimensions for squamous lung carcinomas (pT stage was not available in the query in this histology).

The molecular triggers behind AURKB overexpression in NSCLC are not yet clear. We have investigated a possible relationship between AURKB and KRAS/TP53 status in the studied cancer cell lines, however no such correlation was obtained. This is not surprising, as tumour cell lines are highly abnormal and diverse at the genetic and epigenetic levels, therefore many confounding factors will influence AURKB expression. An interesting observation came from our HBEC isogenic lines (Figure 2), where the addition of mutant KRAS actually significantly reduces AURKB expression, either in the presence or absence of TP53. This is in contrast to a single report available (Dos Santos et al, 2016) which demonstrates upregulation of AURKB by KRAS in a different immortalised lung epithelial cell line. Therefore it is not yet clear whether KRAS has a positive or negative impact on AURKB expression. In contrast, TP53 knockdown is clearly associated with increased AURKB levels. While no evidence for direct transcriptional inhibition of AURKB by p53 exists, a possible mechanism is through c-myc. p53 represses, through induction of miR-145 c-myc (Sachdeva et al, 2009), which is known to induce expression of both AURKA and AURKB (den Hollander et al, 2010).

$A U R K B$ mRNA overexpression alone did not correlate with overall survival, in agreement with two previous studies (Smith et al, 2005; Perumal et al, 2012), although the latter has suggested that $A U R K B$ expression can be part of a prognostic multi-gene signature. In contrast, immunohistochemical analysis of AURKB protein expression was reported to correlate with poor prognosis (Vischioni et al, 2006; Takeshita et al, 2013) suggesting that stability and/or correct localisation of the protein may also be important.

$A U R K B$ mRNA expression was higher in all lung cancer cell lines tested in comparison to HBECs, as has been previously described (Hayama et al, 2007). The most significant observation of this study is the inverse correlation found in NSCLC cell lines between $A U R K B$ mRNA expression and sensitivity to both tested taxanes, with low levels of $A U R K B$ being associated with taxane resistance. The hypothesis that this change in resistance might be simply the reflection of a reduction in doubling times was disproved, as no such correlation was demonstrated. In order to verify the inverse correlation found between the endogenous $A U R K B$ levels and taxane resistance, we knocked down AURKB mRNA expression in two lung cancer cell lines. This knockdown consistently triggered a marked increased resistance to paclitaxel. Moreover, it was observed that different knock down efficiency in each clone led to a different level of resistance to paclitaxel, showing for the first time a quantitative effect between expression of this gene and modulation of resistance to a taxane in human cancer cells.

In order to exclude possible off-target effects of genetic manipulation, we used a highly selective AURKB inhibitor
(Barasertib or AZD1152), which was reported to have a 3700 fold higher specificity for AURKB inhibition in comparison to AURKA (Yang et al, 2007; Walsby et al, 2008). This experiment also demonstrated a clear dose-dependent increase of resistance to paclitaxel with increasing concentrations of Barasertib in all cell lines tested. Barasertib effect, as hypothesised, was moderated when tested in AURKB knockdown clones, due to the already reduced availability of AURKB protein in these clones. This data is in contrast to a previous report suggesting that Aurora B inhibition sensitises cells to antimitotic agents (Tanaka et al, 2007). However, that study utilised a generic kinase inhibitor AT9283, which inhibits Aurora A and other kinases, such as Jak2, Jak3 and Abl kinase as well as Aurora B (Curry et al, 2009). It is well known that Aurora A inhibition enhances chemosensitivity to paclitaxel in pancreatic cancer cells (Lin et al, 2012), to docetaxel in human oesophageal squamous cell carcinoma (Isham et al, 2013) and ovarian cancer cells (Scharer et al, 2008), therefore this 4 . sensitisation can be most probably attributed to AURKA inhibition. The association of high Aurora B kinase expression sensitivity to taxane-based therapy has been also shown for ovarian cancer (Beussel et al, 2012). In addition, miRNA-dependent knockdown of AURKB also results in resistanse to taxanes in an in vivo breast cancer model (Winsel et al, 2014). Therefore the mechanism behind resistance to pacitaxel therapy due to AURKB mitotic checkpoint abrogation is not limited to NSCLC and appears to be getting well established.

Possible mechanisms to explain the effect of Aurora B on taxane efficiency may be drawn from a number of previous observations. Paclitaxel acts by perturbation of mitotic spindle assembly and activating the spindle assembly checkpoint (Zachos et al, 2007; Hung et al, 2008). This leads to a cell death response triggered through p53-independent apoptotic pathways that depend upon maintaining mitotic arrest (Huang et al, 2009). If mitotic slippage occurs, evasion of apoptosis is allowed, mainly due to the stabilisation of anti-apoptotic proteins (Wertz et al, 2011). The use of Aurora B inhibitors (Ditchfield, 2003; Hauf et al, 2003), (Vader et al, 2007; Girdler et al, 2008), deactivation of Aurora B (Wang et al, 2008) or depletion of Aurora B activating proteins (Vader et al, 2007; Petsalaki et al, 2011) have shown to relieve mitotic arrest caused by paclitaxel. Taken together, these studies provide further evidence for the central role of Aurora B function for spindle checkpoint activation and cell death in response to lowdose paclitaxel and further support our findings.

Concerning the evidence so far, AURKB expression presents with a potential paradox: Its overexpression reduces survival in the chemotherapy naïve patients but appears to have a beneficial effect in patients treated with taxane regimens. The latter may draw additional support from the loss of the very strong correlation between AURKB and NSCLC patient survival available online and mentioned in the results section, when limiting the question in the chemotherapy recipient group. Of course 'chemotherapy' term in there is inclusive of every scheme used but nevertheless raises the question for investigating AURKB involvement in the resistance modulation of other common chemotherapeutics.

The present study clearly demonstrated a role for Aurora B in the response of NSCLC cells to paclitaxel and provided unique evidence for a dose-dependent association. Given the large extent of $A U R K B$ deregulation in NSCLC, these findings suggest that assessing the levels of AURKB protein in surgical samples and/or biopsy material could assist in the clinical decision tree for managing patients with NSCLC and have potential for development as a predictive biomarker. Unfortunately, chemotherapy data were not available for our tissue cohort, thus we could not investigate any correlation between $A U R K B$ expression and response to taxanes in this clinical set. Our findings, however, highlight the need for conducting such studies in large cohorts of NSCLC patients. Moreover, it may advise against the use of 
AURKB inhibitors in regimens involving taxanes and this should be further investigated in clinical studies.

\section{ACKNOWLEDGEMENTS}

The Liverpool Lung Project is funded by the Roy Castle Lung Cancer Foundation, UK. This study was also supported through a $\mathrm{PhD}$ studentship awarded to A A-K by the University of Baghdad, Iraq.

\section{CONFLICT OF INTEREST}

The authors declare no conflict of interest.

\section{REFERENCES}

Beussel S, Hasenburg A, Bogatyreva L, Hauschke D, Werner M, Lassmann S (2012) Aurora-B protein expression is linked to initial response to taxane-based first-line chemotherapy in stage III ovarian carcinoma. J Clin Pathol 65(1): 29-35.

Cagle PT, Chirieac LR (2012) Advances in treatment of lung cancer with targeted therapy. Arch Pathol Lab Med 136(5): 504-509.

Camidge DR, Berge EM, Doebele RC, Ballas MS, Jahan T, Haigentz Jr M, Hoffman D, Spicer J, West H, Lee P, Yang L, Joshi A, Gao L, Yurasov S, Mita A (2014) A phase ii, open-label study of ramucirumab in combination with paclitaxel and carboplatin as first-line therapy in patients with stage iiib/iv non-small-cell lung cancer. J Thorac Oncol 9(10): $1532-1539$.

Carmena M, Wheelock M, Funabiki H, Earnshaw WC (2012) The chromosomal passenger complex (CPC): from easy rider to the godfather of mitosis. Nat Rev Mol Cell Biol 13(12): 789-803.

Che CL, Zhang YM, Zhang HH, Sang YL, Lu B, Dong FS, Zhang LJ, Lv FZ (2013) DNA microarray reveals different pathways responding to paclitaxel and docetaxel in non-small cell lung cancer cell line. Int J Clin Exp Pathol 6(8): 1538-1548.

Chu Q, Vincent M, Logan D, Mackay JA, Evans WK (2005) Taxanes as first-line therapy for advanced non-small cell lung cancer: a systematic review and practice guideline. Lung Cancer 50(3): 355-374.

Cottini F, Lautenschlaeger T (2013) Predictors of biomarkers guiding targeted therapeutic strategies in locally advanced lung cancer. Cancer J 19(3): 263-271.

Curry J, Angove H, Fazal L, Lyons J, Reule M, Thompson N, Wallis N (2009) Aurora B kinase inhibition in mitosis: strategies for optimising the use of aurora kinase inhibitors such as AT9283. Cell Cycle 8(12): 1921-1929.

Del Mastro L, Fabi A, Mansutti M, De Laurentiis M, Durando A, Merlo DF, Bruzzi P, La Torre I, Ceccarelli M, Kazeem G, Marchi P, Boy D, Venturini M, De Placido S, Cognetti F (2013) Randomised phase 3 open-label trial of first-line treatment with gemcitabine in association with docetaxel or paclitaxel in women with metastatic breast cancer: a comparison of different schedules and treatments. BMC Cancer 13: 164.

den Hollander J, Rimpi S, Doherty JR, Rudelius M, Buck A, Hoellein A, Kremer M, Graf N, Scheerer M, Hall MA, Goga A, von Bubnoff N, Duyster J, Peschel C, Cleveland JL, Nilsson JA, Keller U (2010) Aurora kinases A and B are up-regulated by Myc and are essential for maintenance of the malignant state. Blood 116(9): 1498-1505.

Ditchfield C (2003) Aurora B couples chromosome alignment with anaphase by targeting BubR1, Mad2, and Cenp-E to kinetochores. J Cell Biol 161(2): 267-280.

Dos Santos EO, Carneiro-Lobo TC, Aoki MN, Levantini E, Basseres DS (2016) Aurora kinase targeting in lung cancer reduces KRAS-induced transformation. Mol Cancer 15: 12.

Eberhard DA, Johnson BE, Amler LC, Goddard AD, Heldens SL, Herbst RS, Ince WL, Janne PA, Januario T, Johnson DH, Klein P, Miller VA, Ostland MA, Ramies DA, Sebisanovic D, Stinson JA, Zhang YR, Seshagiri S, Hillan KJ (2005) Mutations in the epidermal growth factor receptor and in KRAS are predictive and prognostic indicators in patients with non-small-cell lung cancer treated with chemotherapy alone and in combination with erlotinib. J Clin Oncol 23(25): 5900-5909.

Fu J, Bian M, Jiang Q, Zhang C (2007) Roles of Aurora kinases in mitosis and tumorigenesis. Mol Cancer Res 5(1): 1-10.

Girdler F, Sessa F, Patercoli S, Villa F, Musacchio A, Taylor S (2008) Molecular basis of drug resistance in aurora kinases. Chem Biol 15(6): $552-562$.

Glaysher S, Yiannakis D, Gabriel FG, Johnson P, Polak ME, Knight LA, Goldthorpe Z, Peregrin K, Gyi M, Modi P, Rahamim J, Smith ME, Amer K, Addis B, Poole M, Narayanan A, Gulliford TJ, Andreotti PE, Cree IA (2009) Resistance gene expression determines the in vitro chemosensitivity of non-small cell lung cancer (NSCLC). BMC cancer 9 300-317.

Guntur VP, Waldrep JC, Guo JJ, Selting K, Dhand R (2010) Increasing p53 protein sensitizes non-small cell lung cancer to paclitaxel and cisplatin in vitro. Anticancer Res 30(9): 3557-3564.

Hauf S, Cole RW, LaTerra S, Zimmer C, Schnapp G, Walter R, Heckel A, van Meel J, Rieder CL, Peters JM (2003) The small molecule Hesperadin reveals a role for Aurora B in correcting kinetochore-microtubule attachment and in maintaining the spindle assembly checkpoint. J Cell Biol 161(2): 281-294.

Hayama S, Daigo Y, Yamabuki T, Hirata D, Kato T, Miyamoto M, Ito T, Tsuchiya E, Kondo S, Nakamura Y (2007) Phosphorylation and activation of cell division cycle associated 8 by aurora kinase B plays a significant role in human lung carcinogenesis. Cancer Res 67(9): 4113-4122.

Herbst RS, Sun Y, Eberhardt WE, Germonpre P, Saijo N, Zhou C, Wang J, Li L, Kabbinavar F, Ichinose Y, Qin S, Zhang L, Biesma B, Heymach JV, Langmuir P, Kennedy SJ, Tada H, Johnson BE (2010) Vandetanib plus docetaxel versus docetaxel as second-line treatment for patients with advanced non-small-cell lung cancer (ZODIAC): a double-blind, randomised, phase 3 trial. Lancet Oncol 11(7): 619-626.

Huang HC, Shi J, Orth JD, Mitchison TJ (2009) Evidence that mitotic exit is a better cancer therapeutic target than spindle assembly. Cancer cell 16(4): 347-358.

Hung RJ, McKay JD, Gaborieau V, Boffetta P, Hashibe M, Zaridze D, Mukeria A, Szeszenia-Dabrowska N, Lissowska J, Rudnai P, Fabianova E, Mates D, Bencko V, Foretova L, Janout V, Chen C, Goodman G, Field JK, Liloglou T, Xinarianos G, Cassidy A, McLaughlin J, Liu G, Narod S, Krokan HE, Skorpen F, Elvestad MB, Hveem K, Vatten L, Linseisen J, Clavel-Chapelon F, Vineis P, Bueno-de-Mesquita HB, Lund E, Martinez C, Bingham S, Rasmuson T, Hainaut P, Riboli E, Ahrens W, Benhamou S, Lagiou P, Trichopoulos D, Holcatova I, Merletti F, Kjaerheim K, Agudo A, Macfarlane G, Talamini R, Simonato L, Lowry R, Conway DI, Znaor A, Healy C, Zelenika D, Boland A, Delepine M, Foglio M, Lechner D, Matsuda F, Blanche H, Gut I, Heath S, Lathrop M, Brennan P (2008) A susceptibility locus for lung cancer maps to nicotinic acetylcholine receptor subunit genes on 15q25. Nature 452(7187): 633-637.

Isham CR, Bossou AR, Negron V, Fisher KE, Kumar R, Marlow L, Lingle WL, Smallridge RC, Sherman EJ, Suman VJ, Copland JA, Bible KC (2013) Pazopanib enhances paclitaxel-induced mitotic catastrophe in anaplastic thyroid cancer. Sci Transl Med 5(166): 166ra3.

Isonishi S, Suzuki M, Nagano H, Takagi K, Shimauchi M, Kawabata M, Ochiai K (2013) A feasibility study on maintenance of docetaxel after paclitaxel-carboplatin chemotherapy in patients with advanced ovarian cancer. J Gynecol Oncol 24(2): 154-159.

Jinturkar KA, Anish C, Kumar MK, Bagchi T, Panda AK, Misra AR (2012) Liposomal formulations of Etoposide and Docetaxel for p53 mediated enhanced cytotoxicity in lung cancer cell lines. Biomaterials 33(8): 2492-2507.

Kaira K, Takahashi T, Murakami H, Shukuya T, Kenmotsu H, Ono A, Naito T, Tsuya A, Nakamura Y, Endo M, Kondo H, Nakajima T, Yamamoto N (2013) The role of betaIII-tubulin in non-small cell lung cancer patients treated by taxane-based chemotherapy. Int J Clin Oncol 18(3): 371-379.

Kavallaris M, Burkhart CA, Horwitz SB (1999) Antisense oligonucleotides to class III beta-tubulin sensitize drug-resistant cells to Taxol. Br J Cancer 80(7): 1020-1025.

Kris MG, Johnson BE, Berry LD, Kwiatkowski DJ, Iafrate AJ, Wistuba, Varella-Garcia M, Franklin WA, Aronson SL, Su PF, Shyr Y, Camidge DR, Sequist LV, Glisson BS, Khuri FR, Garon EB, Pao W, Rudin C, Schiller J, Haura EB, Socinski M, Shirai K, Chen H, Giaccone G, Ladanyi M, Kugler K, Minna JD, Bunn PA (2014) Using multiplexed assays of 
oncogenic drivers in lung cancers to select targeted drugs. JAMA 311(19): 1998-2006.

Lin Y, Richards FM, Krippendorff BF, Bramhall JL, Harrington JA, Bapiro TE, Robertson A, Zheleva D, Jodrell DI (2012) Paclitaxel and CYC3, an aurora kinase A inhibitor, synergise in pancreatic cancer cells but not bone marrow precursor cells. Br J Cancer 107(10): 1692-1701.

Lin ZZ, Jeng YM, Hu FC, Pan HW, Tsao HW, Lai PL, Lee PH, Cheng AL, Hsu HC (2010) Significance of Aurora B overexpression in hepatocellular carcinoma. Aurora B Overexpression in HCC. BMC Cancer 10: 461.

Maemondo M, Inoue A, Sugawara S, Harada T, Minegishi Y, Usui K, Miwa K, Morikawa N, Kambe M, Ube K, Watanabe K, Ishimoto O, Sakakibara T, Gemma A, Nukiwa T (2014) Randomized phase II trial comparing carboplatin plus weekly paclitaxel and docetaxel alone in elderly patients with advanced non-small cell lung cancer: north japan lung cancer group trial 0801. Oncologist 19(4): 352-353.

Monzo M, Rosell R, Sanchez JJ, Lee JS, O’Brate A, Gonzalez-Larriba JL, Alberola V, Lorenzo JC, Nunez L, Ro JY, Martin C (1999) Paclitaxel resistance in non-small-cell lung cancer associated with beta-tubulin gene mutations. J Clin Oncol 17(6): 1786-1793.

Murray S, Briasoulis E, Linardou H, Bafaloukos D, Papadimitriou C (2012) Taxane resistance in breast cancer: mechanisms, predictive biomarkers and circumvention strategies. Cancer Treat Rev 38(7): 890-903.

Oh IJ, Kim KS, Kim YC, Ban HJ, Kwon YS, Kim YI, Lim SC, Chung WK, Nam TK, Song JY, Yoon MS, Ahn SJ (2013) A phase III concurrent chemoradiotherapy trial with cisplatin and paclitaxel or docetaxel or gemcitabine in unresectable non-small cell lung cancer: KASLC 0401. Cancer Chemother Pharmacol 72(6): 1247-1254.

Perumal D, Singh S, Yoder SJ, Bloom GC, Chellappan SP (2012) A novel five gene signature derived from stem-like side population cells predicts overall and recurrence-free survival in NSCLC. PLoS One 7(8): e43589.

Petsalaki E, Akoumianaki T, Black EJ, Gillespie DA, Zachos G (2011) Phosphorylation at serine 331 is required for Aurora B activation. J Cell Biol 195(3): 449-466.

Pillai RN, Brodie SA, Sica GL, Shaojin Y, Li G, Nickleach DC, Yuan L, Varma VA, Bonta D, Herman JG, Brock MV, Ribeiro MJ, Ramalingam SS, Owonikoko TK, Khuri FR, Brandes JC (2013) CHFR protein expression predicts outcomes to taxane-based first line therapy in metastatic NSCLC. Clin Cancer Res 19(6): 1603-1611.

Pohl A, Azuma M, Zhang W, Yang D, Ning Y, Winder T, Danenberg K, Lenz HJ (2011) Pharmacogenetic profiling of Aurora kinase B is associated with overall survival in metastatic colorectal cancer. Pharmacogenomics $J$ 11(2): 93-99.

Sachdeva M, Zhu S, Wu F, Wu H, Walia V, Kumar S, Elble R, Watabe K, Mo YY (2009) p53 represses c-Myc through induction of the tumor suppressor miR-145. Proc Natl Acad Sci USA 106(9): 3207-3212.

Scharer CD, Laycock N, Osunkoya AO, Logani S, McDonald JF, Benigno BB, Moreno CS (2008) Aurora kinase inhibitors synergize with paclitaxel to induce apoptosis in ovarian cancer cells. J Transl Med 6: 79.

Smith SL, Bowers NL, Betticher DC, Gautschi O, Ratschiller D, Hoban PR, Booton R, Santibanez-Koref MF, Heighway J (2005) Overexpression of aurora B kinase (AURKB) in primary non-small cell lung carcinoma is frequent, generally driven from one allele, and correlates with the level of genetic instability. Br J Cancer 93(6): 719-729.

Sorrentino R, Libertini S, Pallante PL, Troncone G, Palombini L, Bavetsias V, Spalletti-Cernia D, Laccetti P, Linardopoulos S, Chieffi P, Fusco A, Portella G (2005) Aurora B overexpression associates with the thyroid carcinoma undifferentiated phenotype and is required for thyroid carcinoma cell proliferation. J Clin Endocrinol Metab 90(2): 928-935.

Takeshita M, Koga T, Takayama K, Ijichi K, Yano T, Maehara Y, Nakanishi Y, Sueishi K (2013) Aurora-B overexpression is correlated with aneuploidy and poor prognosis in non-small cell lung cancer. Lung Cancer 80(1): $85-90$.

Tanaka E, Hashimoto Y, Ito T, Kondo K, Higashiyama M, Tsunoda S, Ortiz C, Sakai Y, Inazawa J, Shimada Y (2007) The suppression of
aurora-A/STK15/BTAK expression enhances chemosensitivity to docetaxel in human esophageal squamous cell carcinoma. Clin Cancer Res 13(4): 1331-1340.

Travis WD, Brambilla E, Riely GJ (2013) New pathologic classification of lung cancer: relevance for clinical practice and clinical trials. J Clin Oncol 31(8): 992-1001.

Tsao AS, Liu S, Fujimoto J, Wistuba, Lee JJ, Marom EM, Charnsangavej C, Fossella FV, Tran HT, Blumenschein GR, Papadimitrakopoulou V, Kies MS, Hong WK, Stewart DJ (2011) Phase II trials of imatinib mesylate and docetaxel in patients with metastatic non-small cell lung cancer and head and neck squamous cell carcinoma. J Thorac Oncol 6(12): 2104-2111.

Vader G, Cruijsen CW, van Harn T, Vromans MJ, Medema RH, Lens SM (2007) The chromosomal passenger complex controls spindle checkpoint function independent from its role in correcting microtubule kinetochore interactions. Mol Biol Cell 18(11): 4553-4564.

Van Veldhuizen PJ, Reed G, Aggarwal A, Baranda J, Zulfiqar M, Williamson S (2003) Docetaxel and ketoconazole in advanced hormone-refractory prostate carcinoma: a phase I and pharmacokinetic study. Cancer $\mathbf{9 8}(9)$ : $1855-1862$.

Vischioni B, Oudejans JJ, Vos W, Rodriguez JA, Giaccone G (2006) Frequent overexpression of aurora B kinase, a novel drug target, in non-small cell lung carcinoma patients. Mol Cancer Ther 5(11): 2905-2913.

Walsby E, Walsh V, Pepper C, Burnett A, Mills K (2008) Effects of the aurora kinase inhibitors AZD1152-HQPA and ZM447439 on growth arrest and polyploidy in acute myeloid leukemia cell lines and primary blasts. Haematologica 93(5): 662-669.

Wang W, Stukenberg PT, Brautigan DL (2008) Phosphatase inhibitor-2 balances protein phosphatase 1 and aurora B kinase for chromosome segregation and cytokinesis in human retinal epithelial cells. Mol Biol Cell 19(11): 4852-4862.

Wertz IE, Kusam S, Lam C, Okamoto T, Sandoval W, Anderson DJ, Helgason E, Ernst JA, Eby M, Liu J, Belmont LD, Kaminker JS, O’Rourke KM, Pujara K, Kohli PB, Johnson AR, Chiu ML, Lill JR, Jackson PK, Fairbrother WJ, Seshagiri S, Ludlam MJ, Leong KG, Dueber EC, Maecker H, Huang DC, Dixit VM (2011) Sensitivity to antitubulin chemotherapeutics is regulated by MCL1 and FBW7. Nature 471(7336): 110-114.

Winsel S, Maki-Jouppila J, Tambe M, Aure MR, Pruikkonen S, Salmela AL, Halonen T, Leivonen SK, Kallio L, Borresen-Dale AL, Kallio MJ (2014) Excess of miRNA-378a-5p perturbs mitotic fidelity and correlates with breast cancer tumourigenesis in vivo. Br J Cancer 111(11): 2142-2151.

Xu Z, Ogawa H, Vagnarelli P, Bergmann JH, Hudson DF, Ruchaud S, Fukagawa T, Earnshaw WC, Samejima K (2009) INCENP-aurora B interactions modulate kinase activity and chromosome passenger complex localization. J Cell Biol 187(5): 637-653.

Yang J, Ikezoe T, Nishioka C, Tasaka T, Taniguchi A, Kuwayama Y, Komatsu N, Bandobashi K, Togitani K, Koeffler HP, Taguchi H, Yokoyama A (2007) AZD1152, a novel and selective aurora B kinase inhibitor, induces growth arrest, apoptosis, and sensitization for tubulin depolymerizing agent or topoisomerase II inhibitor in human acute leukemia cells in vitro and in vivo. Blood 110(6): 2034-2040.

Zachos G, Black EJ, Walker M, Scott MT, Vagnarelli P, Earnshaw WC, Gillespie DA (2007) Chk1 is required for spindle checkpoint function. Dev Cell 12(2): 247-260.

This work is published under the standard license to publish agreement. After 12 months the work will become freely available and the license terms will switch to a Creative Commons AttributionNonCommercial-Share Alike 4.0 Unported License.

Supplementary Information accompanies this paper on British Journal of Cancer website (http://www.nature.com/bjc) 